Editors' Note: Sethi suggests that neurology is mainly a clinical discipline. Dhand et al. explain that while many neurologic diagnoses are made clinically, some need additional laboratory, imaging, and electrophysiologic testing. The role of cortical cholinergic function on gait in patients with Parkinson disease is further elaborated by Mehanna. The role of acetylcholinesterase inhibitor drugs is, however, modest. Bohnen et al. suggest that drugs that selectively stimulate $\alpha 4 \beta 2\left(^{*}\right)$ nicotinic receptors may be more beneficial. -Chafic Karam, MD, and Robert C. Griggs, MD

\section{HOW EXPERIENCED COMMUNITY NEUROLOGISTS MAKE DIAGNOSES DURING CLINICAL ENCOUNTERS}

Nitin K. Sethi, New York: Dhand et al. ${ }^{1}$ studied the diagnostic practices of community neurologists. Experienced neurologists require little more than patient history supplemented by a general physical and neurologic examination to diagnose disease. They may confirm their diagnosis with the aid of various tests. Ideally, the model for the majority of neurologic diagnoses should be clinical (C) 4, laboratory (L) 1, and neuroimaging (N) 1. A shift to more testing (L4 N4) is due to many factors: the experience level of the neurologist, physician conflict of interest, fear of malpractice liability, and practice setting (academic center vs small community hospital). It would be interesting to replicate this study in different clinical settings in various countries.

Author Response: Amar Dhand, St. Louis; John Engstrom, Gurpreet Dhaliwal, San Francisco: We appreciate Dr. Sethi's comments. Many diagnoses in neurology, like Parkinson disease, are dependent on the clinical domain. However, other conditions are only suggested by clinical findings but require neuroimaging (e.g., multiple sclerosis) or laboratory analysis (e.g., meningitis) to make the diagnosis. As we observed in these disorders, the imaging and laboratory components were equally as important as the information elicited by the history and examination. Therefore, we caution against advancing an overly classical view of neurologic diagnosis; one of the important findings from our study was the variance among disease types. We agree with Dr. Sethi that similar studies in other settings would be valuable. (C) 2014 American Academy of Neurology
1. Dhand A, Engstrom J, Dhaliwal G. How experienced community neurologists make diagnoses during clinical encounters. Neurology 2013;81:1460-1466.

\section{GAIT SPEED IN PARKINSON DISEASE CORRELATES WITH CHOLINERGIC DEGENERATION}

Raja Mehanna, Houston: Bohnen et al. ${ }^{1}$ correlated slowing of gait with cortical cholinergic denervation, rather than nigral dopaminergic denervation, in patients with Parkinson disease (PD). This solidifies the current opinion that PD is the result of more than an isolated dopamine deficit. There was also no correlation with pedunculopontine nucleus (PPN)-thalamic denervation. The benefit of PPN-targeted deep brain stimulation on gait in PD is unclear. ${ }^{2}$ The authors suggested that enhancement of cortical cholinergic function might improve gait disorders in patients with PD. There are scarce but promising data to support this suggestion.

A small open-label study of 9 patients with Alzheimer disease $(\mathrm{AD})$ on galantamine for 6 months showed no improvement when patients only walked, yet it showed improvement when they walked and counted out loud. ${ }^{3}$ This confirms that the effect of denervation of the cholinergic system on gait might be through impairment of the attention and cognition (cortical), rather than the direct locomotion (PPN), network. However, these results could not be replicated in a smaller open-label study of 6 patients with $\mathrm{AD}$ treated with donepezil and 8 untreated patients with mild cognitive impairment serving as controls. ${ }^{4}$ Larger, randomized studies are needed.

Author Response: Nicolaas Bohnen, Martin Sarter, Martijn Muller, William Dauer, Roger Albin, Ann Arbor, MI: We agree with Dr. Mehanna that the clinical effects of acetylcholinesterase inhibitor drugs (AChEIs) are modest at best. Several factors may explain the limited effectiveness of AChEIs. First, our previous in vivo imaging studies have shown that in up to $60 \%$ of subjects with Alzheimer disease, AChEI-induced cerebral acetylcholinesterase inhibition may be too low to induce a relevant effect. ${ }^{5}$ Furthermore, when AChEIs elevate levels of acetylcholine in the brain, high synaptic and extrasynaptic acetylcholine levels may generate unwelcome effects, including 
inhibition of presynaptic cholinergic signaling by stimulation of presynaptic muscarinic type 2 receptors and nonphysiologic, tonic stimulation of postsynaptic nicotinic and muscarinic receptors. ${ }^{6}$ Despite these limitations, mobility benefits of AChEIs have been reported in PD.?

Preliminary data in animal studies suggest that drugs that selectively stimulate $\alpha 4 \beta 2\left(^{*}\right)$ nicotinic receptors not only have excellent entry into the brain but also may improve mobility functions in rats with dual dopaminergic and cholinergic lesions. ${ }^{8}$ Such selective agonists are superior to the nonselective nicotine mother drug because nicotine interferes with the phasic cholinergic activity that is essential for cognitive function. ${ }^{9}$ Further investigation of this class of drugs to treat mobility problems in PD is necessary.

(C) 2014 American Academy of Neurology

1. Bohnen NI, Frey KA, Studenski S, et al. Gait speed in Parkinson disease correlates with cholinergic degeneration. Neurology 2013;81:1611-1616.

2. Potter-Nerger M, Volkmann J. Deep brain stimulation for gait and postural symptoms in Parkinson's disease. Mov Disord 2013;28:1609-1615.
3. Assal F, Allali G, Kressig RW, et al. Galantamine improves gait performance in patients with Alzheimer's disease. J Am Geriatr Soc 2008;56:946-947.

4. Montero-Odasso M, Wells J, Borrie M. Can cognitive enhancers reduce the risk of falls in people with dementia? An open-label study with controls. J Am Geriatr Soc 2009;57:359-360.

5. Bohnen NI, Kaufer DI, Hendrickson R, et al. Degree of inhibition of cortical acetylcholinesterase activity and cognitive effects by donepezil treatment in Alzheimer's disease. J Neurol Neurosurg Psychiatry 2005;76:315-319.

6. Hasselmo ME, Sarter M. Modes and models of forebrain cholinergic neuromodulation of cognition. Neuropsychopharmacology 2011;36:52-73.

7. Litvinenko IV, Odinak MM, Mogil'naya VI, et al. Efficacy and safety of galantamine (reminyl) for dementia in patients with Parkinson's disease (an open controlled trial). Neurosci Behav Physiol 2008;38:937-945.

8. Kucinski A, Paolone G, Bradshaw M, et al. Modeling fall propensity in Parkinson's disease: deficits in the attentional control of complex movements in rats with cortical-cholinergic and striatal-dopaminergic deafferentation. J Neurosci 2013; 33:16522-16539.

9. Howe WM, Ji J, Parikh V, et al. Enhancement of attentional performance by selective stimulation of alphałbeta2 $(*)$ nAChRs: underlying cholinergic mechanisms. Neuropsychopharmacology 2010;35:1391-1401.

\section{CORRECTION}

\section{Tumefactive MS lesions under fingolimod: A case report and literature review}

In the article "Tumefactive MS lesions under fingolimod: A case report and literature review" by G. Pilz et al. (Neurology ${ }^{\circledR}$ 2013;81:1654-1658), there is an error in the description of figure B.c. The description should have read, "Follow-up MRI 6 months later: a new large T2 hyperintense lesion with perifocal edema is seen in the right frontal white matter which shows ring-like gadolinium enhancement (lower panel)." The authors regret the error. 


\section{Neurology}

\section{Gait speed in Parkinson disease correlates with cholinergic degeneration}

Raja Mehanna, Nicolaas Bohnen, Martin Sarter, et al.

Neurology 2014;82;1568-1569

DOI 10.1212/01.wnl.0000446971.02565.f1

This information is current as of April 28, 2014

Updated Information \& Services

References

Permissions \& Licensing

Reprints including high resolution figures, can be found at: http://n.neurology.org/content/82/17/1568.2.full

This article cites 9 articles, 3 of which you can access for free at: http://n.neurology.org/content/82/17/1568.2.full\#ref-list-1

Information about reproducing this article in parts (figures,tables) or in its entirety can be found online at:

http://www.neurology.org/about/about_the_journal\#permissions

Information about ordering reprints can be found online: http://n.neurology.org/subscribers/advertise

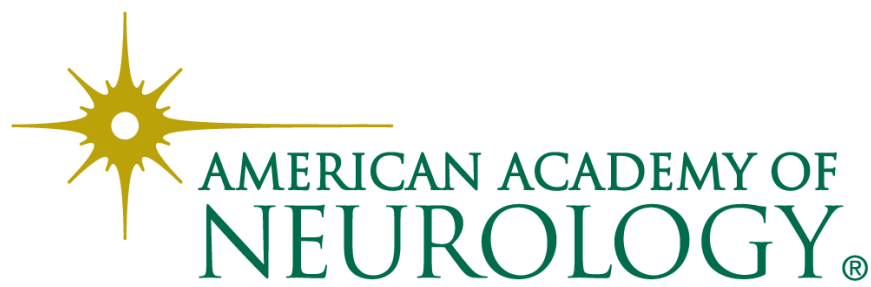

